\title{
Gratidão e sentimento de obrigatoriedade na infância
}

\author{
Paula Grazziotin Silveira Rava - Universidade Federal do Rio Grande do Sul, Porto Alegre/RS, Brasil \\ Lia Beatriz de Lucca Freitas - Universidade Federal do Rio Grande do Sul, Porto Alegre/RS, Brasil
}

\begin{abstract}
Resumo
O estudo examinou como as crianças avaliam: sentimentos do beneficiário diante de uma ação generosa, o tipo de relação estabelecida entre esses sentimentos e o benfeitor, a obrigatoriedade ou não de se retribuir um favor e as justificativas. Participaram 89 crianças de 5 a 12 anos, distribuídas em três grupos etários. Utilizaram-se duas histórias sobre situações cotidianas. A maior parte das crianças estabeleceu relação entre o sentimento positivo do beneficiário e a ação do benfeitor. Os resultados sugerem uma evolução nas concepções das crianças sobre a obrigação de retribuir. As crianças mais jovens foram as que mais apresentaram justificativas de consequência para o benfeitor. A justificativa de retribuição como um bem moral apareceu apenas no grupo de crianças mais velhas.

Palavras-chave: Gratidão; Desenvolvimento moral; Crianças.
\end{abstract}

\section{Gratitude and the feeling of obligation in childhood}

\begin{abstract}
In this study we examined the ways in which children evaluate: the beneficiary's feelings following a generous action, the type of relation established between these feelings and the benefactor, the sense of obligation or not to repay the favor, and the justifications. Participants were 89 5- to 8-year-old children, divided into three age groups. We used two vignettes involving daily occurrences. Most of the children established a relation between the beneficiary's positive feeling and the benefactor's action. The results suggest an evolution in children's conceptions about the obligation to repay the favor. The youngest children were those who were most likely to justify repayment because of consequences to the benefactor. The justification that repayment is a moral good was seen only in the group of older children.

Keywords: Gratitude, Moral development, Children.
\end{abstract}

Gratitud y sentimiento de obligación en la infancia

\begin{abstract}
Resumen
El presente estudio tiene como objetivo examinar cómo los niños evalúan los sentimientos del destinatario delante de una acción generosa, el tipo de relación que establecen entre estos sentimientos y el benefactor, la obligación de volver o no un favor y las justificaciones. Participaron del estudio 89 niños con edades entre 5 y 12 años, divididos en tres grupos de edad. Se utilizaron dos historias sobre situaciones cotidianas. La mayoría de los niños estableció una relación entre el sentimiento positivo del beneficiario y la acción benefactora. Los resultados sugieren una evolución en las concepciones de los niños en la obligación de volver una acción generosa. Los niños más pequeños son los que más presentaron justificaciones de consecuencia para el benefactor. La justificación de la retribución como un bien moral apareció sólo en niños mayores.

Palabras clave: Gratitud; Desarrollo moral; Niños.
\end{abstract}

A gratidão é admirada em diversas culturas e tem sido considerada por autores de diferentes campos do conhecimento como um importante recurso para a manutenção dos vínculos sociais (BaumgartnerTramer, 1938; Bonnie \& de Waal, 2004; Komter, 2004; Simmel, 1950). Observa-se atualmente uma diversidade de conceitos sobre gratidão. Na psicologia, a gratidão é concebida tanto como virtude moral (e.g., La Taille, 2000, 2001) quanto como um sentimento moral (e.g., Baumgarten-Tramer, 1938; Bonnie \& de Waal, 2004; Freitas, Silveira \& Pieta, 2009a; Piaget, 1954/2005, 1965/1973), ou, ainda, emoção (e.g., Frederickson, 2004; Frederickson, Tugade, Waugh \& Larkin, 2003) e afeto (e.g., McCullough, Kilpatrick, Emmons \& Larson, 2001).

Neste estudo, considera-se a gratidão como um sentimento interindividual, ou seja, aquele que é forjado na relação com o outro (Freitas, 1999) a partir de uma ação generosa. A gratidão foi descrita como um sentimento reativo (Baumgarten-Tramer, 1938) ou retributivo (Westermark, 1908/1928) de um indivíduo a uma ação generosa de outro. $\mathrm{O}$ aspecto reativo seria o sentimento do beneficiário diante de uma ação generosa do benfeitor e o aspecto retributivo refere-se à ação que leva o beneficiário a retribuir o benefício recebido. Godbout (1992) afirma que a gratidão emergiria em um ciclo dar - receber - retribuir. O referido autor salienta que esses "três momentos do ciclo geralmente se confundem do ponto de vista do ator, pois dar é retribuir, e vice-versa" (p. 137). Pode-se constatar o caráter da inseparabilidade entre esses três aspectos da gratidão: o dom ou dádiva, a reação diante do recebimento do benefício e a retribuição.

Além de Godbout (1992), Bonnie e de Waal (2004) também entendem que a gratidão ocorreria em um ciclo. Com base na perspectiva etológica, eles propuseram um modelo para explicar os mecanismos da gratidão. Quando um indivíduo recebe uma ação generosa de outro, esta ação dá origem a um bom sentimento. $\mathrm{O}$ beneficiário associa esse sentimento ao benfeitor. Além disso, ele reconhece os custos da ação e atribui boas intenções ao benfeitor. Assim, o beneficiário torna-se grato não apenas pela ação recebida, mas também ao próprio benfeitor. $O$ beneficiário, então, sente uma dívida em relação ao benfeitor e uma obrigação de retribuir o favor. 
Finalmente, o beneficiário retribui o favor ao benfeitor e o ciclo continua, porque o benfeitor inicial (agora beneficiário) sente-se bem, etc.

Esse seria o ciclo completo da troca recíproca que conduziria ao sentimento de gratidão, o qual Bonnie e de Waal (2004) chamaram "Ciclo 3". Todavia o ciclo completo nem sempre aparece em uma troca de serviços. Frequentemente, a retribuição de um favor é feita automaticamente, sem que sentimentos sejam levados em consideração ("Ciclo 1"). Também pode acontecer que um sentimento positivo seja despertado no beneficiário, sem que esse sentimento leve, necessariamente, a uma avaliação dos custos da ação para o benfeitor ou de suas intenções ("Ciclo 2"). Dessa maneira, pode-se despertar uma atitude positiva do beneficiário em relação ao benfeitor, mas não haveria uma valorização positiva do próprio benfeitor e, provavelmente, não surgiria o sentimento de obrigatoriedade de retribuir o favor.

Antes mesmo de Bonnie e de Waal (2004), Piaget (1965/1973) já havia destacado que, na gratidão, o beneficiário valoriza não apenas a ação do benfeitor, mas o próprio benfeitor. É dessa valorização positiva do próprio benfeitor que decorre o sentimento de uma dívida psicológica do beneficiário e uma obrigação de retribuir-lhe o favor. Piaget demonstrou que as trocas de valores não ocorrem aleatoriamente e formulou um modelo para explicar o mecanismo de uma troca social qualquer. Deve-se destacar que este modelo explicativo evidencia a diferença entre a valorização da ação ou serviço e a valorização da pessoa. A partir da semelhança entre esses dois modelos, levantou-se a hipótese (Freitas \& cols., 2009a) de que o modelo de Bonnie e de Waal poderia servir também para explicar o desenvolvimento da gratidão na infância, ou seja, os ciclos mais elementares (Ciclos 1 e 2) apareceriam antes, no desenvolvimento da criança, que o Ciclo 3.

Piaget (1954/2005) sugeriu que a gratidão das crianças menores seria diferente das mais velhas. Ele afirma que "a gratidão seria um sentimento frágil na criança pequena, mas que logo se estabilizaria graças à conservação dos valores e à obrigação moral (autônoma)" (p. 89). Nessa passagem, Piaget enaltece o aspecto do sentimento de obrigatoriedade associado à gratidão. Essa importância dada à conservação de valores para o fortalecimento do sentimento de gratidão também é sustentada pelo antropólogo Godbout (1992) ao definir a retribuição como o ato de conectar um gesto a outro que aconteceu previamente. No campo da filosofia, Comte-Sponville (2007) também enaltece o papel da retribuição conceituando a gratidão como sinônimo de reconhecimento e a ingratidão como a incapacidade de retribuição.

Apesar de a área da psicologia do desenvolvimento já ser consolidada no campo da pesquisa psicológica (Souza, Gauer \& Hutz, 2004), ainda observa-se uma escassez de pesquisas empíricas enfocando o sentimento de gratidão na infância (Froh,
Miller \& Snyder, 2007; Froh, Sefick \& Emmons, 2008; Gordon, Musher-Eizenman, Holub \& Dalrymple, 2004). Além da falta de pesquisas com crianças, destaca-se a controvérsia na literatura sobre a relação entre os sentimentos de gratidão e obrigação (Anderson, 2005; Goei \& Boster, 2005; Watkins, Scheer, Ovnicek \& Kolts, 2006), pois enquanto alguns autores os consideram como equivalentes, outros afirmam tratar-se de estados emocionais distintos.

Uma das formas de estudar-se o desenvolvimento do sentimento de gratidão na infância é buscar acessar como as crianças avaliam situações de troca entre beneficiário e benfeitor. Considerando que a retribuição é, também, um aspecto da gratidão, é importante buscar esclarecer se existe, para as crianças, a obrigatoriedade de retribuir.

Neste artigo, a partir da abordagem construtivista sobre o desenvolvimento moral, busca-se investigar como as crianças avaliam: (a) os sentimentos do beneficiário diante de uma ação generosa; (b) o tipo de relação estabelecida entre esses sentimentos e o benfeitor e (c) a obrigatoriedade ou não de se retribuir um favor. Analisam-se também as suas justificativas para a necessidade ou não de retribuir um favor.

\section{Método}

\section{Participantes}

Participaram deste estudo 89 crianças, distribuídas em três grupos etários: grupo 1 (28 crianças com idade média de 5,9 anos); grupo 2 (29 participantes com idade média de 7,8 anos) e grupo 3 (32 participantes com idade média de 11,8 anos). Cada grupo foi constituído de meninos e meninas, sendo todos alunos de uma escola e uma creche, ambas públicas, de Porto Alegre-RS. A direção de cada instituição assinou a autorização para a realização da pesquisa e os pais ou responsáveis legais das crianças assinaram um termo de consentimento livre e esclarecido.

\section{Instrumentos e procedimentos}

Utilizaram-se duas histórias elaboradas a partir de situações cotidianas das crianças. Cada uma das histórias tinha uma versão masculina e outra feminina. As histórias abordam diferentes temáticas: (a) auxílio na busca de animal de estimação (história da gatinha) e (b) empréstimo de objeto pessoal (história do casaco). Antes do início da pesquisa propriamente dita, realizou-se um estudo piloto com 12 participantes. Adaptaram-se as histórias à linguagem das crianças a partir da maneira como elas as recontavam aos entrevistadores (Freitas \& cols., 2009a, 2009b).

Entrevistaram-se as crianças, individualmente, na instituição escolar que frequentavam. As entrevistas foram gravadas e, posteriormente, transcritas. Após contar cada uma das histórias, solicitava-se à criança que a recontasse e, a seguir, realizava-se uma entrevista 
clínica com perguntas específicas de cada história. As histórias contadas e as perguntas foram as seguintes:

História da gatinha: Ângelo tinha uma gatinha. Um dia ela desapareceu. Tia Ana, que estava fazendo um bolo, disse: "Não tem problema. Eu te ajudo a procurar tua gatinha." Ângelo e tia Ana ficaram muito tempo procurando. No fim do dia, encontraram a gatinha. Tia Ana teve que jogar a massa do bolo fora e começar tudo de novo (versão feminina: Ângela). Como Ângelo se sentiu? Por quê? Ele sentiu mais alguma coisa? Ângelo deve [tem que] ajudar tia Ana a fazer o bolo? Por quê?

História do casaco: Em um dia de inverno, Gabriel estava com frio. João, um menino novo na escola, tinha outro casaco em sua mochila. Então, ele emprestou o casaco para Gabriel (versão feminina: Gabriela e Joana). Como Gabriel se sentiu? Por quê? Ele sentiu mais alguma coisa?

João esqueceu sua tesoura em casa. A professora tinha pedido que todos trouxessem tesoura, naquele dia. Gabriel tem outra tesoura em sua mochila. Ele deve [tem que] emprestar a tesoura para João ou não? Por quê?

Inicialmente, realizou-se uma análise qualitativa das entrevistas, procurando estabelecer as categorias de análise (Delval, 2002). Algumas categorias de análise referentes ao aspecto reativo da gratidão foram provenientes do estudo piloto (Freitas \& cols., 2009a, 2009b). As categorias utilizadas para classificar as justificativas dos participantes, as quais se referem ao aspecto retributivo da gratidão, foram publicadas em estudo prévio (Castro, Rava, Hoefelmann, Pieta, \& Freitas, 2011). Atribuíram-se valores para essas categorias, sendo a primeira delas a mais elementar e a última a categoria de respostas mais elaborada. $\mathrm{Na}$ análise quantitativa dos dados, levou-se em consideração apenas a resposta de maior complexidade de cada participante ao longo da entrevista. Finalmente, levantou-se a frequência dos diferentes tipos de resposta nos grupos etários previamente definidos, usando o teste qui quadrado.

\section{Resultados}

Os resultados obtidos nas duas histórias são apresentados em duas partes: (a) sentimentos atribuídos ao beneficiário diante de uma ação generosa e (b) sentimento de obrigatoriedade de retribuição ao benfeitor prévio. Ilustram-se as categorias de análise com extratos das entrevistas. Após cada extrato, aparecem dados que dizem respeito a: (a) história, (b) participante, (c) sexo do participante e (d) idade da criança. Assim, HG refere-se à história da gatinha e HC refere-se à história do casaco; para preservar a identidade dos participantes, substituíram-se os seus nomes por um conjunto aleatório de três letras; a letra
$\mathrm{M}$ indica participante do sexo masculino e $\mathrm{F}$ indica participante do sexo feminino; a idade é informada em anos e, após ponto e vírgula, o número de meses.

Sentimentos atribuidos ao beneficiário diante de uma ação generosa na história da gatinha e na história do casaco

Para a análise do aspecto reativo da gratidão, primeiramente examinaram-se os participantes que atribuíram sentimentos positivos ao beneficiário. Analisaram-se as seguintes questões: "Como Ângelo se sentiu?"; "Ele sentiu mais alguma coisa?" e, ainda, "Ele sentiu alguma coisa em relação à tia Ana?" (história da gatinha) e "Como Gabriel se sentiu?", "Ele sentiu mais alguma coisa?" e, ainda, "Ele sentiu alguma coisa em relação a João?” (história do casaco).

Um participante foi excluído da amostra, porque sua entrevista sobre a história da gatinha estava incompleta. Os resultados da história da gatinha revelam que $91 \%$ das 88 crianças entrevistadas afirmaram que Ângelo sentiu algum sentimento positivo (bem, feliz, alegre, etc.) ao receber o auxílio da tia. No entanto, sete participantes atribuíram apenas sentimentos negativos (triste, mal, chateado) ao personagem. Destes, dois pertenciam ao grupo 1, quatro ao grupo 2 e um ao grupo 3. No momento de responder às questões, esses participantes não consideraram o auxílio recebido, atendo-se apenas à perda do animal de estimação.

Os resultados da história do casaco mostram que $88,8 \%$ das 89 crianças entrevistadas afirmaram que Gabriel sentiu algum sentimento positivo ao receber o auxílio de João. No entanto, dez participantes atribuíram apenas sentimentos negativos (triste, mal, ruim) ao personagem. Destes, cinco pertenciam ao grupo 1, quatro ao grupo 2 e um ao grupo 3 . No momento de responder às questões, estss participantes não consideraram o auxílio recebido, atendo-se apenas à falta do casaco.

Analisou-se a relação estabelecida pelos participantes entre sentimento positivo atribuído ao beneficiário (qualquer que tenha sido o tipo de sentimento positivo mencionado) e o seu benfeitor, mediante suas respostas às perguntas de justificação. As respostas que as crianças utilizavam para explicar as razões para Ângelo (história da gatinha) e Gabriel (história do casaco) experienciarem esse bom sentimento foram agrupadas em duas categorias distintas: (a) sem relação e (b) com relação. A última foi dividida em duas subcategorias: (a) com a ação e (b) como benfeitor. As respostas que não se adequaram a nenhuma dessas categorias foram agrupadas na categoria outras. A Tabela 1 apresenta a frequência de respostas dos participantes quanto à relação estabelecida pelos participantes entre o sentimento positivo do beneficiário e o benfeitor, em ambas as histórias. 
Tabela 1. Frequência da relação entre sentimento positivo e benfeitor na história da gatinha e na história do casaco

\begin{tabular}{|c|c|c|c|c|c|}
\hline \multicolumn{6}{|c|}{ História da Gatinha } \\
\hline \multirow[t]{2}{*}{ Grupo etário } & \multirow[t]{2}{*}{ Sem relação } & \multicolumn{3}{|c|}{ Com Relação } & \multirow[t]{2}{*}{ Total } \\
\hline & & \multicolumn{2}{|l|}{ Ação } & Benfeitor & \\
\hline Grupo 1 & 10 & \multicolumn{2}{|l|}{15} & 1 & 26 \\
\hline Grupo 2 & 9 & \multicolumn{2}{|l|}{13} & 3 & 25 \\
\hline Grupo 3 & 9 & \multicolumn{2}{|l|}{18} & 3 & 30 \\
\hline Total & 28 & \multicolumn{2}{|c|}{46} & 7 & 81 \\
\hline \multicolumn{6}{|c|}{ História do Casaco } \\
\hline \multirow[t]{2}{*}{ Grupo etário } & \multirow[t]{2}{*}{ Sem relação } & \multicolumn{2}{|c|}{ Com Relação } & \multirow[t]{2}{*}{ Outras } & \multirow[t]{2}{*}{ Total } \\
\hline & & Ação & Benfeitor & & \\
\hline Grupo 1 & 4 & 17 & 0 & 2 & 23 \\
\hline Grupo 2 & 4 & 18 & 3 & 0 & 25 \\
\hline Grupo 3 & 5 & 17 & 9 & 0 & 31 \\
\hline Total & 13 & 52 & 12 & 2 & 79 \\
\hline
\end{tabular}

$\mathrm{Na}$ categoria sem relação, incluíram-se as respostas em que o participante refere-se a um ou mais sentimentos positivos, mas não as relaciona com o benfeitor.

E ele sentiu mais alguma coisa além de felicidade?

$\mathrm{Não}$. Tu achas que sentiu alguma coisa pela tia

Ana? Não. (HG, Ben, F, 6;9)

Como Gabriel se sentiu? Feliz, porque ele tava quente.

E ele sentiu alguma coisa pelo João? Feliz: Por quê? Porque ele não tinha mais frio. (HC, Ali, M, 7;1)

$\mathrm{Na}$ categoria com relação, incluíram-se as respostas dos participantes que estabeleceram algum tipo de relação entre o sentimento positivo do beneficiário e o benfeitor. Na subcategoria relação com a ação, foram inseridas as respostas em que o participante se refere a um ou mais sentimentos positivos, mas os relaciona apenas à ação do benfeitor.

Quando ele achou a gatinha, como ele se sentiu? Bem feliz: Por quê? Porque ele achou a gatinha dele. É? Mais alguma coisa ele sentiu? Acho que não. Ele sentiu alguma coisa pela tia Ana? Gostou por ela te ajudado. (HG, Eli, M, 8;2)

E como é que é isso, que ele sentiu? Amizade pelo João. É? Por quê? Por causa do casaco, ele empreston o casaco pro Gabriel. E ele sentiu mais alguma coisa? Não. (HC, Dum, M, 8;11)

A subcategoria relação com o benfeitor reuniu as respostas em que o participante se refere a um ou mais sentimentos, dirigidos ao próprio benfeitor e não apenas à sua ação.

Como é que a Ângela se sentiu? Muito feliz por ter encontrado o gatinho e triste porque tinha perdido antes de encontrar. E ela sentiu mais alguma coisa? Que a tia dela era muito amiga dela. E por que ela sentiu isso? Porque a tia dela deixon o bolo de lado e foi lá ajudar. Aham. E ela sentiu mais alguma coisa em relação à tia dela? Sentiu que ela era muito legal. (HG, Baq, F, $8 ; 8)$

A Gabriela sentiu alguma coisa pela Joana? Sentiu que ela podia fazer uma amizade com ela. Como é que é isso, poder fazer amizade? Ser amiga dela e brincar.
Por que ela sentiu que podia ser amiga dela? Porque en acho que ela sentiu que ela era uma garota legal. (HC, Sig, F, 7;0)

Utilizou-se o teste qui quadrado (usando o teste exato de Fisher) para verificar se existiria alguma diferença entre os grupos etários quanto ao tipo de relação estabelecida entre sentimento positivo e benfeitor (com a sua ação ou com o benfeitor propriamente dito). Não houve diferença significativa entre a referida questão e os grupos etários na história da gatinha, $X^{2}=1,157, p>0,5$.

$\mathrm{Na}$ história do casaco, constatou-se diferença significativa entre os grupos etários, no que se refere ao tipo de relação estabelecida entre sentimento positivo e benfeitor, $X^{2}=8,46, p<0,02$. Isso se deve ao fato de que a relação entre sentimento positivo e benfeitor aumentou de acordo com a idade das crianças, sendo que a valorização do próprio benfeitor apareceu com maior frequência no grupo 3 .

Sentimento de obrigatoriedade de retribuição ao benfeitor prévio na história da gatinha e na história do casaco

$\mathrm{Na}$ análise dos dados das histórias que avaliam o sentimento de obrigatoriedade de retribuir o favor, consideraram-se: (a) a obrigação ou não de retribuição e (b) as justificativas apresentadas pelas crianças. Ao responder à pergunta Angelo deve ajudar a tia Ana a fazer o bolo ou não? Por quê? (história da gatinha) as crianças mencionaram respostas que foram classificadas em três diferentes categorias: (a) deve, (b) não deve e (c) pode. A maioria das crianças (81\%) disse que Ângelo deveria auxiliar sua tia a fazer o bolo - essa foi a resposta mais frequentemente encontrada nos participantes independentemente da faixa etária. O segundo tipo de resposta mais frequente $(16 \%)$ foi aquele que se classificou como "pode", pois, embora as crianças tenham afirmado que Ângelo deveria ajudar a tia Ana, suas justificativas indicaram que Angelo poderia ajudar a tia se ele quisesse, ou seja, não havia um sentimento de obrigatoriedade. Apenas duas crianças (3\%) 
responderam que ele não deveria auxiliar, sendo que uma delas respondeu simplesmente "porque não" (HG, Bas, F, 5;2), e, então, ficou a dúvida se a ação de ajudar seria, para essa participante, algo reprovável. Outro participante respondeu "não, porque ele é pequeno" (HG, Ben, $\mathrm{M}, 7 ; 0)$, provavelmente em razão de ter escutado anteriormente de seus pais ou responsáveis que tal ação (fazer o bolo) não é adequada para crianças.

Examinaram-se especificamente as respostas afirmativas (categorias deve e pode) para a questão "Ângelo deve ajudar a tia Ana a fazer o bolo ou não?". Constatou-se que as respostas para essa questão não variaram de forma significativa entre os grupos etários, $X^{2}=1,27, p>0,5$.

Examinou-se o aspecto retributivo na história do casaco mediante a análise das respostas dos participantes às questões: "Gabriel deve [tem que] emprestar a tesoura para João ou não? Por quê?" A maioria das crianças $(92,1 \%)$ disse que Gabriel deveria emprestar sua tesoura para o colega. No entanto, 7,9\% dos participantes tiveram suas respostas inseridas na categoria pode. Dessa vez, nenhuma criança respondeu que $\mathrm{o}$ (a) personagem não deveria emprestar a tesoura para o(a) colega. Examinaram-se as respostas para a questão "Gabriel deve emprestar a tesoura ou não?" e constatou-se que as respostas para essa questão não variaram de forma significativa entre os grupos etários, $X^{2}=0,3, p>0,05$.

Analisaram-se as justificativas dos participantes cujas respostas foram classificadas na categoria deve. Classificaram-se as justificativas das crianças em três categorias: (a) consequência, (b) obrigação social e (c) bem moral. As justificativas que não se adequaram a nenhuma dessas categorias foram agrupadas na categoria outras. $\mathrm{Na}$ Tabela 2, apresentam-se as frequências dos tipos de justificativa dos participantes por grupo etário, em ambas as histórias.

Tabela 2. Frequência das justificativas da história da gatinha e da história do casaco

\begin{tabular}{|c|c|c|c|c|c|c|}
\hline \multicolumn{7}{|c|}{ História da Gatinha } \\
\hline & Consequência & Obrigação & Bem moral & Não obrigação & Outras & Total \\
\hline Grupo 1 & 14 & 6 & 0 & 3 & 5 & 28 \\
\hline Grupo 2 & 6 & 11 & 0 & 7 & 5 & 29 \\
\hline Grupo 3 & 5 & 14 & 6 & 4 & 2 & 31 \\
\hline Total & 25 & 31 & 6 & 14 & 12 & 88 \\
\hline \multicolumn{7}{|c|}{ História do Casaco } \\
\hline & Consequência & Obrigação & Bem moral & Não obrigação & Outras & Total \\
\hline Grupo 1 & 15 & 9 & 0 & 2 & 2 & 28 \\
\hline Grupo 2 & 5 & 20 & 0 & 2 & 2 & 29 \\
\hline Grupo 3 & 2 & 15 & 8 & 3 & 4 & 32 \\
\hline Total & 22 & 44 & 8 & 7 & 8 & 89 \\
\hline
\end{tabular}

$\mathrm{Na}$ categoria consequência, foram inseridas as justificativas em que o vínculo afetivo com o outro ou $\mathrm{o}$ interesse pelo objeto (bolo/tesoura) parecem ser suficientes para justificar a ação benevolente (ajudar/emprestar). Ajudar a fazer o bolo visa a agradar a tia Ana ou a auxiliar no processo de preparação do bolo. Dessa maneira, a não realização da ação traria um prejuízo - material ou psicológico - para o benfeitor (tia Ana ou João).

$\mathrm{Na}$ história da gatinha, se Ângelo não ajudasse, traria um prejuízo psicológico para a tia Ana (ela ficaria cansada, triste, furiosa etc.) ou para a preparação do bolo (demoraria mais tempo): Se não ajudar, a tia fica furiosa ( $\mathrm{HG}$, Jem, F, 5;5).

$\mathrm{Na}$ história do casaco, se Gabriel não emprestasse, isso traria um prejuízo para João, pois ele ficaria triste, chateado, a professora poderia puni-lo, etc. Outra possibilidade seria ele ficar sem o objeto de que necessitava, não podendo fazer o trabalho.

Ele deve emprestar a tesoura pro João ou não? Sim. Por que sim? Porque senão o João não tinha como recortar (HC, Sam, M, 7; 0).

$\mathrm{Na}$ categoria obrigação social, as justificativas dos participantes indicavam que ajudar é uma forma de Psico-USF, Bragança Paulista, v. 18, n. 3, p. 383-394, set/dez 2013 retribuição, de agradecimento à ação benevolente. A retribuição por parte do beneficiário visa a evitar que os outros o julguem mal ou a reparar o dano causado. A não realização da ação traria um prejuízo para o beneficiário e não (ou não apenas) para o benfeitor. Assim, a criança justifica que se ele não retribuísse, seria considerado mau, mal-agradecido, mal-educado, egoísta, ingrato, preguiçoso, seria castigado por Deus: Tá errado não ajudar, é uma pessoa mal desagradecida (HG, Umb, M, 9;6). Outro exemplo: E se a Gabriela não emprestar a tesoura, que tu irias pensar da Gabriela? Egoísta (HC, Mar, F, 6;11).

Ainda, quando o beneficiário necessitasse de ajuda novamente, não seria ajudado pelo benfeitor: Porque se ela não ajudar a fazer o bolo ela também nunca mais vai ajudar (HG, Giu, F, 6;7). E se ela não emprestar? Ai a Joana não empresta mais nada, porque ela não empreston a tesoura (HC, Hus, F, 8;2).

Para algumas crianças, se o beneficiário não ajudasse, o benfeitor não seria mais amigo dele: $\mathrm{E}$ se a Gabriela não emprestar? Ah, dai ela não ia ser amiga, daí isso não é amizade (HC, Caf, F, 7;0).

$\mathrm{Na}$ categoria bem moral, as justificativas dos participantes mostraram que a retribuição é sentida 
como obrigatória. Todavia, esse sentimento não decorre de uma exigência socialmente imposta ao sujeito. Não é por causa do juízo alheio que o indivíduo deve retribuir. A retribuição é um valor, é boa ("legal"), é justa. Ajudar a fazer o bolo é uma forma de retribuição, de agradecimento à ação benevolente da tia Ana. A pessoa que retribui é "legal" como aquela que fez a benesse (igualdade no sentido de valor equivalente). Retribuir o benefício recebido faz a pessoa sentir-se bem e é uma forma de gratidão:

Acho que seria uma forma de retribuir o que ela fez por ele. Porque seria quase que um sentimento de justiça né?[...] Acho que ele tinha que ajudar ela pra recuperar tempo, pra demonstrar que ele tava grato pelo o que ela fer. (HG, Pan, M, 12;0). O João ajudou ele naquela hora e não seria justo. Imagina: o João ajudon ele e o Gabriel deveria retribuir o favor, né? (HC, Pem, M, 12;2).

$\mathrm{Na}$ categoria não obrigação foram agrupadas todas as justificativas dos participantes cujas respostas às perguntas "Ângelo deve ajudar a tia Ana a fazer o bolo ou não?" e "Gabriel deve emprestar a tesoura para João ou não?" foram classificadas como pode. Esse tipo de resposta não apareceu com frequência suficiente para que se criassem subcategorias para suas justificativas. Para essas crianças, a retribuição não é (ou não deve ser) uma obrigação. Assim como o benfeitor quis fazer a ação generosa, o beneficiário também precisa querer retribuir. A retribuição depende apenas de uma decisão livre do indivíduo. Ela pode porque a tia dela não foi obrigada. Ela fez. porque quis, então não tem obrigatoriedade assim de ajudar ( $\mathrm{HG}, \mathrm{Fal}, \mathrm{F}, 12 ; 10)$. Tanto far, ela pode emprestar ou pode não emprestar ( $\mathrm{HC}, \mathrm{Clo}$, F, 9; 3).

Analisaram-se separadamente as respostas dos participantes que disseram que o personagem deve auxiliar/emprestar e cujas justificativas para tal dever foram classificadas nas categorias consequência, obrigação social e bem moral. Observou-se, na história da gatinha, pelo teste Fisher, que os tipos de justificativa variaram significativamente entre os grupos etários, $X^{2}=16,19$, $p<0,001$. Constatou-se, na história do casaco, também uma variação significativa entre os tipos de justificativas e os grupos etários, $X^{2}=28,76, p<0,001$. Os resultados nas duas histórias provavelmente devemse às diferenças entre as justificativas utilizadas pelas crianças do grupo 1 (principalmente consequência) e o fato de que a retribuição como bem moral apareceu apenas no grupo 3 .

\section{Discussão}

Os resultados revelam que nas duas histórias as crianças, de modo geral, atribuíram sentimentos positivos ao beneficiário da ação generosa. Essa capacidade de experienciar um bom sentimento ou uma satisfação diante de uma boa ação tem sido descrita como condição necessária à gratidão (Bonnie \& de Waal, 2004; Komter, 2004; Piaget, 1954/2005).
Todavia, alguns participantes (sete crianças na história da gatinha e dez crianças na história do casaco) mencionaram apenas sentimentos negativos. Esses sentimentos foram atribuídos à personagem beneficiária antes do recebimento da ação generosa.

Os resultados mostram ainda que algumas crianças não estabeleceram qualquer relação entre o sentimento positivo despertado no beneficiário e o benfeitor. $\mathrm{Na}$ história da gatinha, 28 crianças não estabeleceram relação entre o sentimento prazeroso do personagem e o fato de a tia ter auxiliado na busca do animal de estimação perdido. Na história do casaco, 13 respostas foram categorizadas como sem relação. Chama a atenção o número maior desse tipo de resposta obtido na história da gatinha, em que o benfeitor era um adulto da família, em comparação com a história do casaco, em que o favor foi praticado por outra criança. Talvez esse dado indique que alguns participantes esperem que as pessoas da família se ajudem mutuamente. Esse resultado vai ao encontro de um dado da literatura que afirma que as pessoas, quando são beneficiadas por pessoas próximas, como no caso de familiares, tendem a expressar gratidão em menor grau do que quando são beneficiadas por pessoas mais distantes (McCullough \& cols., 2001).

Parece que o fato do benefício ser proveniente de outra criança facilitou a conexão entre o bom sentimento e a relação com o benfeitor. François (1953) afirmou que o sentimento de gratidão é fomentado na relação entre crianças, ou seja, para a criança é mais fácil o reconhecimento de uma dívida quando o benfeitor é outra criança. Uma das explicações para esse fenômeno é que, nas relações entre pares, as quais são descritas como cooperativas por Piaget (1932/1994), não há um elemento de autoridade ou prestígio, caracterizando uma relação simétrica de poder, em que aquele que recebe um benefício hoje poderá ser um benfeitor amanhã. Outra explicação possível para a maior frequência de respostas na categoria sem relação na história da gatinha em relação à história do casaco refere-se ao tipo de situação proposta. Na história da gatinha, o que está em jogo é a busca pelo animal de estimação perdido; na história do casaco, é o empréstimo de um objeto pessoal. Talvez o conteúdo abordado nas histórias tenha favorecido a ligação entre o bom sentimento do personagem e a relação com o benfeitor. A experiência do empréstimo de um objeto está presente no cotidiano de um maior número de crianças, e os pais e professores enfatizam o papel do benfeitor nessas situações.

A categoria com relação englobou as respostas dos participantes que estabeleceram algum tipo de relação entre a satisfação do beneficiário e o benfeitor ou sua ação. Observando o padrão geral de respostas, pode-se constatar que a maior parte das crianças estabeleceu prioritariamente a relação entre o sentimento positivo do beneficiário e a ação do benfeitor. Esse dado sugere 
que entre o "ciclo 2" (um sentimento positivo sem relação com a ação generosa) e o "ciclo 3" (valorização do benfeitor) propostos por Bonnie e de Waal (2004), existiria uma etapa em que a criança ainda não valoriza o benfeitor, mas já relaciona a sua satisfação com a ação deste, valorizando-a. Esse resultado foi obtido de maneira semelhante nas duas histórias investigadas e sustenta a hipótese anteriormente levantada por Freitas e colaboradores (2009a).

Todavia, do ponto de vista quantitativo, encontrou-se uma diferença entre as duas histórias. $\mathrm{Na}$ história da gatinha, não houve diferença significativa entre os grupos etários quanto ao tipo de relação estabelecida entre sentimento positivo e benfeitor (com a sua ação ou com o benfeitor propriamente dito), enquanto na história do casaco encontrou-se diferença significativa para esse aspecto da gratidão. $\mathrm{Na}$ história do casaco, a relação entre o sentimento positivo do beneficiário e o benfeitor aumentou de acordo com a idade dos participantes, sendo que o grupo 3 foi o que mais estabeleceu esse tipo de relação. $\mathrm{O}$ mesmo não se verificou na história da gatinha. Esse resultado sustenta parcialmente a hipótese anteriormente levantada (Freitas \& cols., 2009a, 2009b) de que existiria uma evolução na infância quanto ao tipo de relação estabelecida entre sentimento positivo e benfeitor.

No que se refere ao aspecto retributivo da gratidão, investigou-se a opinião das crianças sobre a obrigatoriedade de retribuição do favor recebido, e também foram analisadas as justificativas de suas respostas. Os resultados mostram que a maior parte das crianças ( $81 \%$ na história da gatinha e 92\% na história do casaco) afirmou que o beneficiário deve retribuir o favor recebido ao benfeitor prévio. Esse dado também evidencia, contudo, que para algumas crianças a retribuição ao benfeitor prévio não é obrigatória. Novamente, chama a atenção o maior número desse tipo de resposta obtido na história da gatinha, em que o benfeitor era um adulto da família, em comparação com a história do casaco, em que o favor foi praticado por outra criança. Apenas duas crianças disseram que o beneficiário não deveria retribuir o favor, e isto ocorreu somente na história da gatinha.

Os participantes empregaram diferentes tipos de justificativa para a obrigatoriedade de se retribuir um favor, as quais foram classificadas em três categorias: (a) consequência, (b) obrigação social e (c) bem moral. Constatou-se uma variação significativa entre os tipos de justificativa e os grupos etários em ambas as histórias, sendo que as justificativas categorizadas como consequência foram mais frequentemente encontradas no grupo 1 e as justificativas denominadas bem moral foram encontradas apenas no grupo 3. Esta constatação já havia sido feita em estudo anteriormente realizado com uma amostra menor (Castro \& cols., 2011). Nota-se que essas respostas mais elaboradas e ilustrativas da moral da cooperação só aparecem no

Psico-USF, Bragança Paulista, v. 18, n. 3, p. 383-394, set/dez 2013 grupo de idade mais avançada. Apesar disso, percebese que as justificativas mais elementares do tipo consequência ainda permanecem.

Pode-se notar uma evolução na maneira das crianças conceberem a obrigação de retribuir ao benfeitor prévio. $\mathrm{O}$ enfoque nas consequências para $\mathrm{O}$ benfeitor, tipicamente utilizado pelas crianças menores, diminuiu com a idade. No segundo grupo etário, a justificativa mais enfatizada foi a obrigação para evitar um juízo alheio negativo, e a retribuição como um bem moral surgiu apenas no terceiro grupo etário.

A categoria obrigação social refere-se às respostas em que a retribuição é sentida como obrigatória pelas crianças para evitar o juízo alheio negativo e o sentimento de obrigatoriedade ainda não parece estar internalizado. Essa ideia evidencia que é o outro que regula o comportamento, parecendo ser, portanto, representativo da moral da obediência, isto é, da moral heterônoma (Piaget, 1932/1994), a qual se fundamenta nas relações de coação.

$\mathrm{Na}$ categoria bem moral estão agrupadas as respostas das crianças que revelam que o dever de retribuir o benefício recebido é justificado por um motivo próprio do sujeito: "Da mesma forma que a Joana na semana passada tinha emprestado pra ela o casaco que tava guardado na mochila acho que é certo ela emprestar a tesoura que tava dentro da mochila dela e ela não tava usando" (HC, Ces, F, 12;0). A participante explicita que para se retribuir um benefício recebido é necessário, primeiramente, que se conserve na memória esse episódio. Ela também relaciona a gratidão com a satisfação obtida pela boa ação de outra pessoa e a valorização associada. Piaget (1954/2005) ressalta o papel fundamental da capacidade de conservação que o avanço do desenvolvimento possibilita. No plano afetivo, as transformações oriundas da crescente capacidade de representação permitem que os sentimentos conquistem estabilidade e duração, as quais não são possíveis em níveis mais elementares do desenvolvimento infantil. Essa situação de valorização da pessoa que presta o benefício está de acordo com o modelo de Bonnie e de Waal (2004), que propõem que esse seria o ciclo completo (ciclo 3) da troca recíproca que conduziria ao sentimento de gratidão. Outra questão que chama a atenção é o fato de a participante justificar a necessidade de retribuição a partir da compaixão pelo sofrimento alheio, que é um sentimento oriundo de uma preocupação tipicamente moral, como refere La Taille (2006). Talvez o sentimento de gratidão em seu aspecto retributivo possa desempenhar um papel importante na moralidade ao lado de outros sentimentos morais, como a compaixão, a generosidade e a vergonha. As justificativas denominadas bem moral evidenciam o argumento da justiça para explicar a necessidade de retribuição, o que não surpreende, pois "tal primazia encontra-se na história da filosofia moral" (La Taille, 2009, p. 65). Piaget (1932/1994) dedicou-se ao estudo 
da noção de justiça na criança em suas pesquisas sobre o juízo moral, e Kohlberg (1981) desenvolveu sua teoria do desenvolvimento moral dando à justiça um valor primordial. As crianças deste estudo confirmam a importância da justiça, utilizando essa virtude que é "boa em si mesma" (Comte-Sponville, 2007) como argumento para ressaltar a necessidade de retribuição de uma ação generosa. Esse é, talvez, um indicador de que a gratidão, em seu aspecto retributivo, tem seu papel no universo moral e na gênese da moralidade infantil, pois não é à toa que esses sujeitos utilizam argumentos conhecidamente morais, como a bondade e a justiça, para a garantia da necessidade de se retribuir um favor. Vê-se que, aqui, eles parecem estar convencidos de tal necessidade, pois ela já não é mais imposta de fora pelos pais ou professores, como nas respostas das categorias anteriores. Esse pode ser um sinalizador de que elas revelam, em suas reflexões sobre a ação do personagem da história, expressões típicas da autonomia moral descrita por Piaget (1932/1994).

As tentativas de reparar o prejuízo causado à tia trazem o argumento da responsabilidade, que é tão essencial à moralidade. Age moralmente aquele que é capaz de assumir a responsabilidade perante o outro, mesmo quando não houve intenção de lhe causar prejuízo (La Taille, 2009). A avaliação por parte do benfeitor do custo da ação do beneficiário é um elemento importante na compreensão da gratidão (Bonnie \& de Waal, 2004; McCullough, 2002) e pode estar relacionada com a esfera moral, quando impulsiona o sujeito a reconhecer a sua parcela de responsabilidade no dano causado ao outro. As seguintes verbalizações evidenciam esse fato: "Porque um pouco foi culpa dele dela ter perdido o bolo, né?" (HG, Nub, M, 12;7); "Porque ele não pediu ajuda, mas a tia foi ajudar e por causa do gatinho dele o bolo estragou" (HG, Sel, M, 12;4). Na referida história, a generosidade da tia ao ajudar seu sobrinho lhe causa um dano que é o bolo perdido. O fato de a criança reconhecer-se como responsável provavelmente assegura uma preocupação nitidamente moral, conforme ilustra essa justificativa para a necessidade de retribuição da boa ação.

Embora tenham sido questionadas somente sobre o dever de retribuir, algumas crianças, cujas respostas foram categorizadas como não obrigação, revelam que a retribuição não é um dever, mas sim uma possibilidade. Turiel (1983) afirmou que as crianças são capazes de compreender e distinguir os domínios pessoal, moral e convencional, sendo que é no domínio moral que as regras são sentidas como universais e obrigatórias. Assim, parece que, para essas crianças, a retribuição estaria relacionada ao domínio pessoal.

\section{Considerações finais}

A gratidão não apenas estimularia o comportamento moral, mas também poderia ser importante na própria constituição da moralidade (Freitas, Pieta \& Tudge, 2011). Uma vez que não há consciência moral sem sentimento de obrigatoriedade (Freitas, 2003; La Taille, 2006) e que este se desenvolve na infância - da simples obediência a uma norma externa ao sentimento de obrigação moral, pode-se perguntar: qual seria o lugar da gratidão no universo moral infantil? Pode-se pensar que ela estaria situada entre o sentimento de justiça e o sentimento de generosidade. Ela faria fronteira entre os domínios aretaico e deôntico, pois quando se tem um benfeitor, ela torna-se um dever para com aquela pessoa. Não fosse assim, a ingratidão não seria condenável nas diferentes culturas. A análise das respostas das crianças evidencia empiricamente o que McConnell (1993) propõe: a gratidão situa-se na fronteira entre a justiça e a generosidade. $O$ estudo de virtudes que estão na periferia da moralidade - caso da gratidão, entre outras - torna-se tão fundamental para a psicologia moral quanto para o estudo de virtudes centrais, como é o caso da justiça (McConnell, 1993). As crianças mais jovens tendem a ser menos altruístas que as mais velhas por sua dificuldade em visualizar os atos pró-sociais em termos de ganhos e sua tendência a concebê-los em termos de custos (Lourenço, 1992). Certamente "aprender a dar, sem ficar a perder" (Godbout, 1992, p. 44) consiste numa importante aquisição da criança para seu desenvolvimento moral. A verbalização de um participante justifica a necessidade de retribuição pelo bom sentimento que ela desperta em seu interior: "pra ele ficar bem assim, mentalmente” (HG, Jur, M, 12;3).

A obrigatoriedade da retribuição faz parte do universo infantil; porém as crianças não justificam essa obrigatoriedade sempre da mesma maneira. Há uma variação de acordo com a idade. As análises estatísticas revelam que há uma evolução nas frequências das categorias conforme o grupo etário. Essa evolução se dá no sentido das respostas do tipo consequência para o benfeitor, encontradas com maior frequência nas crianças menores, para as justificativas do tipo obrigação social e bem moral, que foram mais evidentes nas crianças maiores.

Uma limitação deste estudo foi a falta de uma integração entre os aspectos reativo e retributivo da gratidão. Para estudos futuros, seria interessante investigar o comportamento dos participantes comparando-se as respostas de uma mesma criança no que se refere à relação estabelecida entre o bom sentimento e o benfeitor e a necessidade de retribuição. Outra limitação é o fato de ter-se utilizado um delineamento transversal, não permitindo o acompanhamento de um mesmo indivíduo em seus diversos momentos evolutivos. Sugere-se que estudos 
futuros sobre a evolução do sentimento de gratidão utilizem o delineamento longitudinal.

\section{Referências}

Anderson, N. H. (2005). How sharper than a serpent's tooth. Journal of Social and Clinical Psychology, 24(7), 1077-1080.

Baumgarten-Tramer, F. (1938). "Gratefulness" in children and young people. Journal of Genetic Psychology, 53, 53-66.

Bonnie, K. E. \& de Waal, B. M. (2004). Primate social reciprocity and the origin of gratitude. Em R. A. Emmons \& M. E. McCullough (Eds.), The psychology of gratitude (pp. 213-229). Nova Iorque: Oxford University Press.

Castro, F. M. P., Rava, P. G. S., Hoefelmann, T. B., Pieta, M. A. M. \& Freitas, L. B. L. (2011). Deve-se retribuir? Gratidão e dívida simbólica na infância. Estudos de Psicologia (Natal), 16(1), 75-82.

Comte-Sponville, A. (2007). Pequeno tratado das grandes virtudes (E. Brandão, Trad.). São Paulo: Martins Fontes.

Delval, J. (2002). Introdução à prática do método clínico: descobrindo o pensamento das crianças. Porto Alegre: Artmed.

François, C. (1953). The psychology of the ungrateful child. Enfance, 6, 159-166.

Frederickson, B. L. (2004). Gratitude, like other positive emotions, broadens and builds. Em R. A. Emmons \& M. E. McCullough (Eds.), The psychology of gratitude (pp. 145-166). Nova Iorque: Oxford University Press.

Frederickson, B. L., Tugade, M. M., Waugh, C. E. \& Larkin, G. R. (2003). What good are positive emotions in crises? A prospective study of resilience and emotions following the terrorist attacks on the United States on september 11th, 2001. Journal of Personality and Social Psychology, 84(2), 365-376.

Freitas, L. B. L. (1999). Do mundo amoral à possibilidade de ação moral. Psicologia: Reflexão $e$ Crítica, 12(2), 447-458.

Freitas, L. B. L. (2003). A moral na obra de Jean Piaget: um projeto inacabado. São Paulo: Cortez.

Freitas, L. B. L., Pieta, M. A. M. \& Tudge, J. R. H. (2011). Beyond politeness: the expression of gratitude in children and adolescents. Psicologia: Reflexão e Crítica, 24(4), 757-764.

Freitas, L. B. L., Silveira, P. G. \& Pieta, M. A. M. (2009a). Sentimento de gratidão em crianças de 5 a 12 anos. Psicologia em Estudo, 14(2), 243-250.

Freitas, L. B. L., Silveira, P. G., \& Pieta, M. A. M. (2009b). Um estudo sobre o desenvolvimento da gratidão na infância. Revista Interamericana de Psicologia, 43(1), 22-29.
Froh, J. J., Miller, D. N. \& Snyder, S. (2007). Gratitude in children and adolescents: development, assessment, and school-based intervention. School Psychology Forum: Research in Practice, 2(1), 1-13.

Froh, J. J., Sefick, W. J. \& Emmons, R. A. (2008). Counting blessings in early adolescents: an experimental study of gratitude and subjective well-being. Journal of School Psychology, 46, 213-233.

Godbout, J. T. (1992). O espirito da dádiva (J. P. Cabrera, Trad.). Lisboa: Instituto Piaget.

Goei, R., \& Boster, F. (2005). The roles of obligation and gratitude in explaining the effect of favors on compliance. Comunication Monografiphs, 72(3), 284300.

Gordon, A. K., Musher-Eizenman, D. R., Holub, S. C. \& Dalrymple, J. (2004). What are children thankful for? An archival analysis of gratitude before and after the attacks of september 11 . Journal of Applied Developmental Psychology, 25(5), 541-553.

Kohlberg, L. (1981). Essays on moral development. São Francisco, CA: Harper \& Row.

Komter, A. E. (2004). Gratitude and gift exchange. Em R. A. Emmons \& M. E. McCoullough (Eds.) The psychology of gratitude (pp. 195-212). Nova Iorque: Oxford University Press.

La Taille, Y. de (2000). Para um estudo psicológico das virtudes morais. Educação e Pesquisa, 26(2), 109122.

La Taille, Y. de (2001). Desenvolvimento moral: a polidez segundo as crianças. Cadernos de Pesquisa, 114, 89-119.

La Taille, Y. de (2006). Moral e ética: dimensões intelectuais e afetivas. Porto Alegre: Artmed.

La Taille, Y. de (2009). As virtudes segundo os jovens. Em Y. de La Taille \& M. S. de S. Menin (Eds.), Crise de valores ou valores em crise? (pp. 46-69). Porto Alegre: Artmed.

La Taille, Y. de (2006). Moral e ética: Dimensões intelectuais e afetivas. Porto Alegre: Artmed.

Lourenço, O. (1992). Para uma explicação piagetiana do aumento do altruísmo na criança: alguns dados interculturais. Revista Portuguesa de Pedagogia, 26(2), 301-319.

McConnell, T. (1993). Gratitude. Filadélfia: Temple University Press.

McCullough, M. E. (2002). Savoring life: past and present: explaining what hope and gratitude share in common. Psychological Inquiry, 13(4), 302-304.

McCullough, M. E., Kilpatrick, S. D., Emmons, R. A. \& Larson, D. B. (2001). Is gratitude a moral affect? Psychological Bulletin, 127(2), 249-266.

Piaget, J. (1973). Estudos sociológicos (R. Di Piero, Trad.). Rio de Janeiro: Forense. (Original publicado em 1965).

Piaget, J. (1994). O juízo moral na criança (3. ed.). (E. Lenardon, Trad.). São Paulo: Summus. (Original publicado em 1932). 
Piaget, J. (2005). Inteligencia y afectividad. (M. S. Dorín, Trad). Buenos Aires: Aique (Original publicado em 1954).

Simmel, G. (1950). The sociology of Georg Simmel. Glencoe, IL: Free Press.

Souza, L. K., Gauer, G. 7 Hutz, C. (2004). Publicações em psicologia do desenvolvimento em dois periódicos nacionais na década de 1990. PsicoUSF, 9(1), 49-57.

Turiel, E. (1983). The development of social knowledge: morality and convention. Cambridge: Cambridge University Press.
Watkins, P. C., Scheer, J., Ovnicek, M. \& Kolts, R. (2006). The debt of gratitude: dissociating gratitude and indebtedness. Cognition and Emotion, 20(2), 217-241.

Westermarck, E. (1928). L'origine et le développement des idées morales. Paris: Payot. (Original publicado em 1908).

Recebido em 02/07/2012

Reformulado em 15/04/2013

Aprovado em 17/04/2013 
Nota do autor:

Este artigo é baseado na Tese de Doutorado da primeira autora, realizada sob orientação da segunda. O estudo desenvolvido nessa tese faz parte de um projeto mais amplo intitulado "O sentimento de gratidão e suas relações com a moralidade: uma abordagem psicogenética". As autoras agradecem a Fernanda Palhares, Maria Adélia Minghelli Pieta e Tatiana Buchabqui Hoefelmann por sua colaboração na coleta e análise dos dados. Agradecem ainda o CNPq pelo auxílio financeiro (Processo $n^{\circ}$ 401900/2007-0), bem como a CAPES, a FAPERGS e o Programa Pibic CNPq/UFRGS pelas bolsas de estudo concedidas às estudantes.

Sobre os autores:

Lia Beatriz de Lucca Freitas é psicóloga, doutora em Psicologia (Universidade de São Paulo), pós-doutorado e estágio sênior no exterior (University of North Carolina at Greensboro, USA), professora do Instituto de Psicologia e do Programa de Pós-Graduação em Psicologia da Universidade Federal do Rio Grande do Sul, coordenadora do LAPEGE - Laboratório de Psicologia e Epistemologia Genética, Pesquisadora do CNPq.

Paula Grazziotin Silveira Rava é psicóloga, doutora em Psicologia (Universidade Federal do Rio Grande do Sul), mestre em Psicologia (PUCRS), professora da Faculdade de Psicologia da Pontifícia Universidade Católica do Rio Grande do Sul - PUCRS.

\section{Contato com as autoras:}

Universidade Federal do Rio Grande do Sul - Instituto de Psicologia

Rua Ramiro Barcelos, 2600 sala 118 - CEP 90035-003 - Porto Alegre/RS

E-mail:paulagraz@yahoo.com 
